\title{
Desempenho inicial de cultivares de feijão submetidas a diferentes profundidades de semeadura
}

\author{
Early performance of common bean cultivars submitted to different sowing depths \\ Maira Maier Bisato, Clovis Arruda de Souza*, Camila Cigel e Rodrigo Kandler \\ Universidade do Estado de Santa Catarina, Lages, SC, Brasil. Autor para correspondência: souza_clovis@yahoo.com.br
}

Submissão: 01/11/2019 / Aceite: 12/05/2021

\begin{abstract}
RESUMO
A profundidade de semeadura pode afetar negativamente a emergência, desenvolvimento inicial de plântulas de feijão e consequentemente o estande de plantas. Porém, o desempenho sob diferentes profundidades pode ser variável entre as cultivares. Objetivou-se neste estudo verificar o efeito de diferentes profundidades de semeadura sobre a emergência e o desenvolvimento inicial de plântulas de cultivares de feijão. O experimento foi conduzido em delineamento em blocos completamente casualizado, em esquema fatorial $4 \times 4$, com quatro repetições. Os fatores consistiram em quatro profundidades de semeadura (4, 8, 10 e 12 centímetros) e quatro cultivares de feijão (TAA Dama, BRS Estilo, IPR Tangará e IPR Tuiuiu). Foram avaliadas as variáveis emergência, índice de velocidade de emergência, comprimento de raiz principal, hipocótilo e epicótilo, e massa seca de plântulas. Observou-se que profundidades de semeadura entre 6 e $10 \mathrm{~cm}$ proporcionaram maior emergência de plântulas com $98 \%$, e IVE de 11,3 , além de favorecer o desempenho inicial de plântulas de feijão. Não houve diferença entre as cultivares para comprimento de hipocótilo e massa seca de plântulas. Concluiu-se que profundidades de semeadura entre 6 e $10 \mathrm{~cm}$, de solo destorroado e descompactado, proporcionam maior emergência e consequente desempenho inicial de plântulas; no entanto, não havendo efeitos distinto das cultivares de feijão.
\end{abstract}

PALAVRAS-CHAVE: germinação; emergência; Phaseolus vulgaris; genótipo.

\begin{abstract}
The sowing depth can negatively affect the emergence and initial development of bean seedlings and, consequently, the plant stand. However, performance under different depths may vary among cultivars. The objective of this study was to verify the effect of different sowing depths on the emergence and initial development of seedlings of bean cultivars. The experiment was conducted in a completely randomized block design, in a $4 \times 4$ factorial layout, with four replications. The factors consisted of four sowing depths $(4 \mathrm{~cm}, 8 \mathrm{~cm}, 10 \mathrm{~cm}$, and $12 \mathrm{~cm}$ ) and four bean cultivars (TAA Dama, BRS Estilo, IPR Tangará, and IPR Tuiuiu). The variables emergence, emergence speed index, main root, hypocotyl, and epicotyl lengths, and seedling dry mass were evaluated. It was observed that sowing depths from $6 \mathrm{~cm}$ to $10 \mathrm{~cm}$ provided greater seedling emergence with $98 \%$ and IVE of 11.3, in addition to favoring the initial performance of bean seedlings. There was no difference between cultivars for hypocotyl length and seedling dry mass. It was concluded that sowing depths from $6 \mathrm{~cm}$ to $10 \mathrm{~cm}$ of unpaved and unpacked soil provide greater emergence and consequent initial seedling performance; however, there are no distinct effects for bean cultivars.
\end{abstract}

KEYWORDS: germination; emergency; Phaseolus vulgaris; genotype.

\section{INTRODUÇÃO}

O feijão pertencente a espécie Phaseolus vulgaris L., é o "tipo de feijão" em que o grão é o mais produzido e consumido no mundo (FAO 2019). A leguminosa possui grande destaque no setor agrícola, cujos grãos constituem uma fonte nutricional de proteínas, boa fonte de lisina, fibras alimentares, carboidratos complexos, minerais como cálcio e ferro, além de vitaminas do complexo B (SILVA et al. 2009), apresentado assim notória importância socioeconômica, além de ser uma cultura alternativa promissora (TAVARES et al. 2013).

Segundo estimativas da Companhia Nacional de Abastecimento (CONAB 2019), a produção 
brasileira total de feijão na safra 2019/20 deve apresentar redução de 54,3 mil toneladas, correspondente a $1,8 \%$ a menos que a safra anterior. Além disto, as previsões apontam para produtividade $0,6 \%$ menor comparada com a safra 2018/19, de $1031 \mathrm{~kg} \mathrm{ha}^{-1}$. A estimativa de produção da leguminosa no estado de Santa Catarina também demonstra redução, correspondente a $7,8 \%$, sendo a estimativa de produção de 97,4 mil toneladas na safra 2019/20.

Devido ao extenso melhoramento de plantas, o $P$. vulgaris compreende inúmeros cultivares com uma vasta gama de características morfológicas e agronômicas, incluindo diferenças na cor e tamanho da semente, bem como hábito de crescimento (PURSEGLOVE 1968), contudo a média da produtividade brasileira não aumentou mesmo com potencial produtivo elevado de cultivares atualmente comercializadas (BIEZUS et al. 2017).

A profundidade de semeadura e a distribuição de sementes na linha são os fatores que mais afetam o desempenho produtivo. Desta maneira a profundidade adequada de semeadura assegura adequada germinação e a obtenção do estande inicial apropriado ao bom desenvolvimento (RODRIGUES et al. 2016), visto que o $P$. vulgaris tem um sistema radicular baseado na raiz axial com raízes laterais tipicamente localizadas nos $15 \mathrm{~cm}$ superiores do solo (PURSEGLOVE 1968). Além disto, a profundidade da deposição das sementes é característica para cada espécie e quando adequada, garante germinação e plântulas uniformes na emergência (TROGELLO et al. 2013).

Profundidades excessivas de semeadura podem impedir a emergência de plântulas devido ao excesso de solo e provocar o esgotamento das reservas da semente; mas por outro lado, semeaduras muito superficiais podem expor a semente a variações ambientais excessivas, como estresse por excesso ou déficit água ou calor, e isso pode dar origem a plântulas pequenas e fracas (SILVEIRA et al. 2018). Portanto, a deposição da semente deve ocorrer em uma profundidade que permita um adequado contato com a umidade do solo, sem irregularidades que afetem a disposição das sementes e que possam provocar perdas futuras de produtividade.

Desta forma, em estudo com a cultura do feijão, BIEZUS et al. (2017) observaram para o grupo de feijão carioca médias superiores nas análises do desempenho de plântulas na maior parte das profundidades testadas $(1 \mathrm{a} 8 \mathrm{~cm}$ ), além de indicar a profundidade de semeadura de $2 \mathrm{~cm}$ para os grupos Cavalo, Preto, Jalo e Carioca. Já PEDÓ et al. (2014) verificaram para as cultivares IPR Gralha e IPR Tiziu que o aumento da profundidade de semeadura reduz o desempenho das plântulas e a expressão do vigor destas. Contudo, MODOLO et al. (2011) verificaram que a profundidade de $5 \mathrm{~cm}$ de semeadura proporcionou melhor índice de velocidade de emergência de plântulas de feijão cultivar UTF 6.

Assim, mais uma vez se ressalta a importância dos estudos que envolvam o vigor de plântulas de diferentes cultivares e o desenvolvimento inicial das plântulas quando submetidas a distintas profundidades de semeadura (PEDÓ et al. 2014). Neste contexto, objetivou-se no presente estudo avaliar os efeitos de diferentes profundidades de semeadura sobre a emergência e o desenvolvimento de plântulas de cultivares de feijão.

\section{MATERIAL E MÉTODOS}

O experimento foi realizado em condições de campo, na Universidade do Estado de Santa Catarina Centro de Ciências Agroveterinárias (UDESC - CAV), no período de 13 de novembro a 06 de dezembro de 2018, no município de Lages, localizado no planalto Sul do estado de Santa Catarina; cujas coordenadas geográficas são $27^{\circ} 52^{\prime} 30^{\prime \prime}$ de latitude sul e $50^{\circ} 18^{\prime} 20^{\prime \prime}$ de longitude oeste, com altitude média de $930 \mathrm{~m}$. Os dados meteorológicos foram obtidos do Instituto Nacional de Meteorologia, da estação de Lages, SC. As informações de temperatura máxima, média, mínima e precipitação pluvial durante a realização do experimento são ilustrados na Figura 1.

O solo da área experimental é classificado como Cambissolo húmico alumínico (EMBRAPA 2013). As propriedades químicas do solo na camada $0-20 \mathrm{~cm}$, segundo análise de solo realizada em outubro de 2018 , foram apresentadas na Tabela 1. A semeadura das cultivares de feijão e adubação foi realizada manualmente, utilizando o fertilizante formulado 02-20-20, com $40 \mathrm{~g} \cdot \mathrm{m}^{-2}$, de acordo com a Comissão de Química e Fertilidade do Solo - RS/SC (CQFS 2016).

$O$ delineamento experimental adotado foi em blocos casualizados, em esquema fatorial $4 \times 4 \mathrm{com}$ quatro repetições. O primeiro fator foi constituído por quatro cultivares de feijão (TAA Dama, BRS Estilo, IPR Tangará e IPR Tuiuiu) e o segundo por quatro profundidades de semeadura $(4 \mathrm{~cm}, 8 \mathrm{~cm}, 10 \mathrm{~cm}$ e $12 \mathrm{~cm}$ ), totalizando 64 parcelas experimentais. As sementes utilizadas foram adquiridas e eram classificadas como categoria S1 (TAA Dama e IPR Tangará) e S2 (BRS Estilo e IPR Tuiuiu), provenientes da safra agrícola de produção 2017/18. 


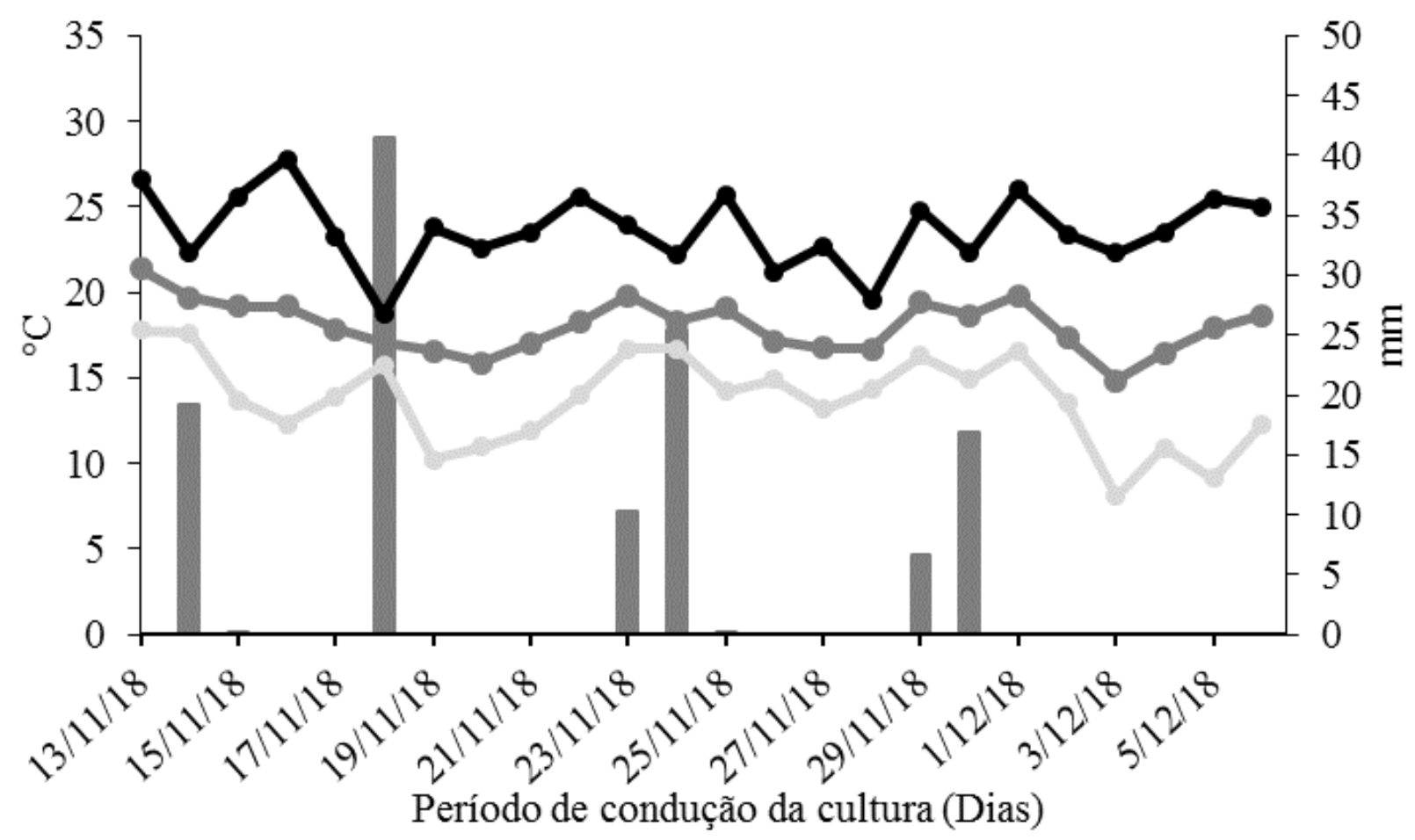

Figura 1. Precipitação pluviométrica e temperaturas (máxima, média e mínima) diárias durante o experimento. Lages, SC, 2018. Fonte: INMET 2019.

Figure 1. Daily rainfall and temperatures (maximum, average, and minimum) during the experiment. Lages, SC, Brazil, 2018. Source: INMET 2019.

Tabela 1. Análise físico-química do solo da área experimental da UDESC-CAV. Lages, SC, 2018.

Table 1. Physicochemical analysis of the soil of the experimental area of UDESC-CAV. Lages, SC, Brazil, 2018.

\begin{tabular}{|c|c|c|c|c|c|c|c|c|c|c|}
\hline Amostras & Argila & $\mathrm{V}$ & M.O & $\begin{array}{c}\mathrm{pH} \\
\left(\mathrm{H}_{2} \mathrm{O}\right)\end{array}$ & $\begin{array}{c}\mathrm{P} \\
\text { Mehlich-1 }\end{array}$ & $\mathrm{K}$ & $\mathrm{Ca}$ & $\mathrm{Mg}$ & $\mathrm{H}^{+}+\mathrm{Al}^{+3}$ & $\begin{array}{r}\text { CTC } \\
(\mathrm{pH} 7)\end{array}$ \\
\hline & ----. & & --- & & $---\mathrm{mg} \cdot \mathrm{dm}^{-3}$ & & & ----- & $\mathrm{nol}_{\mathrm{c}} \cdot \mathrm{dm}$ & ---- \\
\hline $0-20 \mathrm{~cm}$ & 47 & 79 & 2,7 & 5,8 & 20,2 & 1,8 & 7,7 & 5,7 & 3,5 & 17,3 \\
\hline
\end{tabular}

Cada unidade experimental foi constituída por uma linha de semeadura contendo 50 sementes. $O$ espaçamento entrelinhas utilizado foi de $17 \mathrm{~cm}$. O preparo do solo foi realizado de forma manual, com a retirada do solo até a profundidade desejada, conforme descrito por PINHEIRO et al. (2018). Posteriormente, realizou-se a adubação à lanço, semeadura manual e, então, a cobertura das sementes com solo peneirado em malha com crivo de $2 \times 2 \mathrm{~cm}$, com quantidade de solo correspondente a cada tratamento. $O$ controle de plantas daninhas foi efetuado manualmente e o suprimento de água foi realizado via chuva e complementado via irrigação diária conforme a necessidade.

Quando as plântulas começaram a emergir, iniciaram-se as contagens diárias destas, para avaliação do percentual de emergência e cálculo de IVE (índice de velocidade de emergência) (MAGUIRE 1962); para avaliação do comprimento de plântulas utilizou-se a metodologia proposta por NAKAGAWA (1999). Tais avaliações foram realizadas até o momento em que houve o estabelecimento da população sem alteração no número de plântulas emergidas por três dias consecutivos de avaliação. Após esta data, procedeu-se a coleta de plântulas, coletando-se 20 plântulas por parcela, medindo-se o comprimento total das plântulas normais com auxílio de uma régua, comprimento da parte aérea (epicótilo), hipocótilo e raiz, cujos resultados foram expressos em centímetros. Após estas avaliações, tanto as partes aéreas quanto as raízes foram submetidas a secagem até massa constante, em estufa regulada a $60^{\circ} \mathrm{C}$ por 72 horas.

Os resultados obtidos foram submetidos à análise de variância e avaliados pelo teste $\mathrm{F}$ a $5 \%$ de significância. Os dados qualitativos (cultivares) significativos foram submetidos ao teste de médias de Tukey a $5 \%$ de probabilidade de erro e os dados quantitativos (profundidades) a ajustes de regressão quando houve diferença significativa. Utilizou-se o programa estatístico R (R-CORE TEAM 2017). 


\section{RESULTADOS}

A análise de variância indicou existir efeito simples de cultivar e de profundidade para as variáveis testadas (Tabela 2). A emergência das plântulas de feijão variou conforme a cultivar, sendo IPR Tangará, o genótipo com menor percentual, de 78\%. Já para as cultivares TAA Dama, BRS Estilo e IPR Tuiuiu, o percentual de emergência foi superior, atingindo média de $90 \%$ (Figura 2a). A profundidade de semeadura apresentou ajuste quadrático, com acréscimos no percentual de emergência nas profundidades de 8 e $10 \mathrm{~cm}(93 \%)$, e redução em $12 \mathrm{~cm}(69 \%)$. A profundidade estimada com maior percentual de emergência (98\%) para as cultivares de feijão foi em 6,7 cm (Figura 2b).

Tabela 2. Resumo da ANOVA para percentual de emergência (EM), índice de velocidade de emergência (IVE), massa seca total da planta (MST), epicótilo (EPI), hipocótilo (HIP), raiz principal (CR) e comprimento total de plântula (CTP) de cultivares de feijão cultivadas em diferentes profundidades de semeadura.

Table 2. Summary of ANOVA for emergence percentage (EM), emergence speed index (IVE), total plant dry mass (MST), and epicotyl (EPI), hypocotyl (HIP), main root (CR), and total seedling (CTP) lengths of bean cultivars cultivated at different sowing depths.

\begin{tabular}{|c|c|c|c|c|c|c|}
\hline \multirow{2}{*}{ Fontes de Variação } & \multirow[b]{2}{*}{$\mathrm{GL}$} & \multicolumn{5}{|c|}{ QM } \\
\hline & & EM & IVE & & & \\
\hline Bloco & 1 & 0,00 & 0,85 & & & \\
\hline Cultivar (C) & 3 & $0,07^{* \star 1}$ & $6,10^{\star *}$ & & & \\
\hline Profundidade $(\mathrm{P})$ & 3 & $0,20^{\star *}$ & $34,00^{* *}$ & & & \\
\hline $\mathrm{C} \times \mathrm{P}$ & 9 & 0,01 & 0,77 & & & \\
\hline Erro & 15 & 0,00 & 0,39 & & & \\
\hline CV (\%) & & 5,54 & 6,57 & & & \\
\hline Média & & 87,00 & 9,15 & & & \\
\hline Fontes de Variação & $\overline{G L}$ & $\mathrm{MST}^{¥}$ & $\mathrm{EPI}^{*}$ & $\mathrm{HIP}^{¥}$ & $\mathrm{CR}^{*}$ & CTP \\
\hline Bloco & 3 & 0,17 & 0,01 & $0,11^{* *}$ & 0,07 & 7,23 \\
\hline Cultivar (C) & 3 & 0,25 & $0,18^{* *}$ & 0,02 & $0,43^{\star *}$ & $19,95^{*}$ \\
\hline Profundidade $(P)$ & 3 & $1,31^{* *}$ & $1,37^{* *}$ & $0,24^{* *}$ & $2,98^{* *}$ & $244,77^{\prime}$ \\
\hline $\mathrm{C} \times \mathrm{P}$ & 9 & 0,19 & 0,06 & 0,01 & 0,02 & 4,23 \\
\hline Erro & 45 & 0,09 & 0,04 & 0,02 & 0,08 & 5,74 \\
\hline CV (\%) & & 10,22 & 6,43 & 9,08 & 8,23 & 11,01 \\
\hline Média & & 8,72 & 8,76 & 2,14 & 10,97 & 21,77 \\
\hline
\end{tabular}

${ }^{*}$ e ${ }^{* *}$ significativos pelo teste F a 5 e 1\%, respectivamente. GL: Graus de Liberdade; QM: Quadrado Médio; CV (\%): Coeficiente de Variação. ${ }^{\ddagger}$ Valores transformados por $(x+0,5)^{0,5}$.

Um comportamento semelhante ao da emergência foi observado para o índice de velocidade de emergência (IVE). Houve variação no IVE conforme a cultivar testada bem como em função da profundidade de semeadura. A cultivar BRS Estilo se destacou com maior IVE (9,9), seguida de IPR Tuiuiu. Já a cultivar IPR Tangará apresentou menor valor, sendo estes $24,4 \%$ menor em comparação com a cultivar BRS Estilo (Figura 2c). Em relação à profundidade, o IVE apresentou comportamento quadrático, com o maior índice (IVE de 11,4) em $7,3 \mathrm{~cm}$ de profundidade de semeadura (Figura 2d).

O comprimento da raiz principal $(\mathrm{CR})$ das plântulas de feijão apresentou diferença entre as cultivares. Para a cultivar TAA Dama observou-se redução de $22,2 \%$ no $\mathrm{CR}$, em relação as cultivares BRS Estilo, IPR Tangará e IPR Tuiuiu (Figura 3a). Para o fator profundidade de semeadura, os resultados apresentaram comportamento quadrático, com maior valor para o comprimento de raiz principal $(12,7 \mathrm{~cm})$ obtido sobre cultivos a $10,5 \mathrm{~cm}$ de profundidade de semeadura (Figura $3 b$ ).

Para o comprimento do epicótilo das plântulas, IPR Tuiuiu apresentou maiores valores, não diferindo apenas da cultivar TAA Dama e IPR Tangará. Já para o genótipo BRS Estilo observou-se redução de 15,3\% no comprimento quando comparado a cultivar IPR Tuiuiu (Figura 3c). Quanto ao efeito da profundidade de semeadura, observou-se ajuste quadrático, com acréscimos no comprimento do epicótilo das plântulas de feijão, sendo o máximo valor de $8 \mathrm{~cm}$ obtido na semeadura em 10,6 cm de profundidade (Figura 3d). 
a)

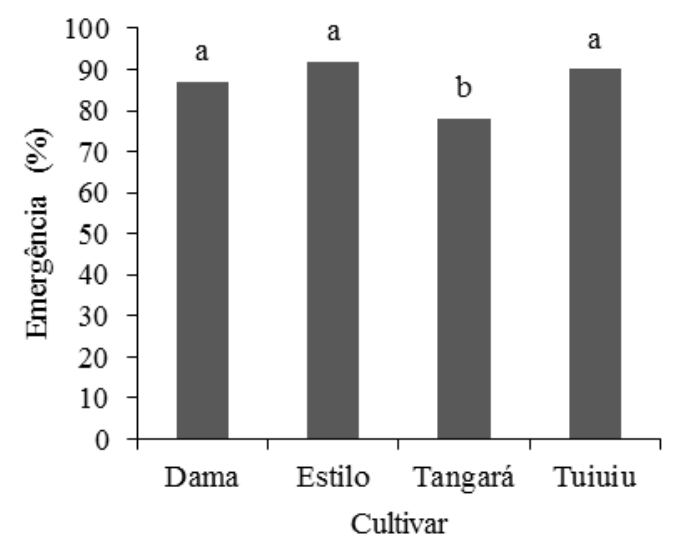

c)

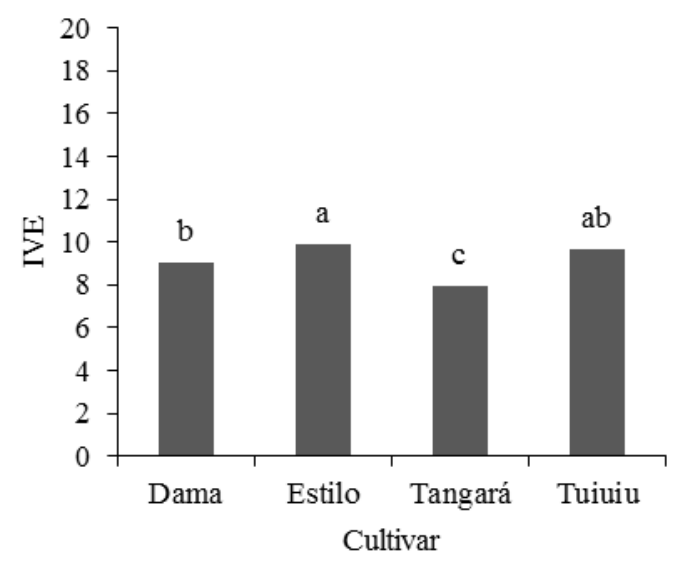

b)

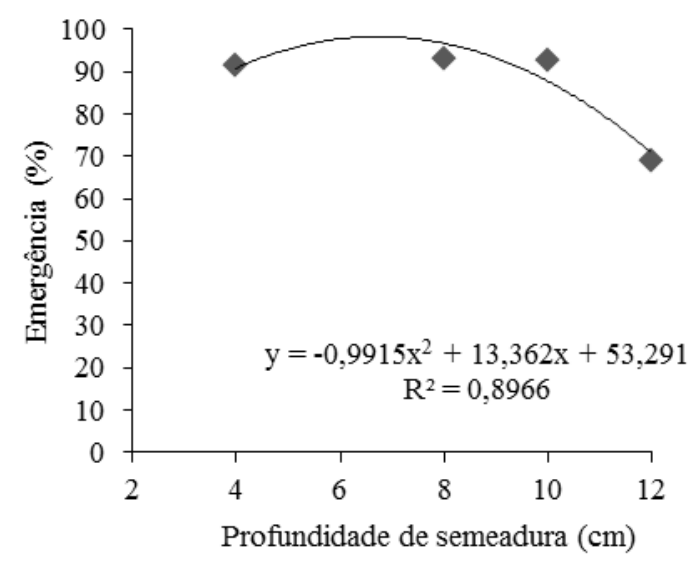

d)

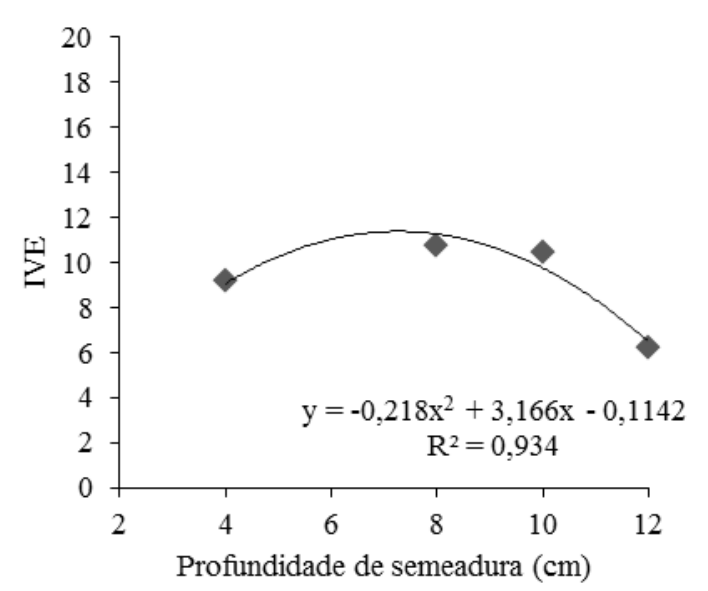

Figura 2. Percentual de emergência (a; b), e índice de velocidade de emergência (c; d) de plântulas de feijão em função de cultivares e de profundidades de semeadura.

Figure 2. Percentage of emergence $(a ; b)$ and emergence rate index $(c ; d)$ of bean seedlings as a function of cultivars and sowing depths.

O comprimento do hipocótilo foi afetado apenas pela profundidade de semeadura. Na média, as cultivares apresentaram valor de hipocótilo de $2,1 \mathrm{~cm}$ (Figura 3e). Observou-se comportamento linear com decréscimo de $0,10 \mathrm{~cm}$ no comprimento do hipocótilo das plântulas de feijão para cada um centímetro de aumento da profundidade de semeadura (Figura 3f).

A altura das plântulas de feijão apresentou comportamento variável entre as cultivares. A cultivar IPR Tuiuiu apresentou acréscimo na altura de plântulas, com média de $23,3 \mathrm{~cm}$. Para a cultivar TAA Dama observou-se redução de 12,6 \% na altura de plântulas, em relação a IPR Tuiuiu (Figura 4a). Em relação a profundidade, houve efeito quadrático, com os valores de maior altura observados na semeadura em $8 \mathrm{e}$ $10 \mathrm{~cm}$, com 23,7 e $25,9 \mathrm{~cm}$. Plântulas de menor altura foram obtidas quando as semeaduras ocorreram em 12 e em $4 \mathrm{~cm}$, com reduções de 26,2 e $53,2 \%$ respectivamente, quando comparadas com a altura das plântulas com semeadura em $8 \mathrm{~cm}$ (Figura 4b).

A massa seca total (MS) das plântulas de feijão não apresentou diferença entre as cultivares, sendo que a média foi de $8,7 \mathrm{~g}$ (Figura 4c). Em relação as profundidades, a MS apresentou efeito simples e com comportamento quadrático, sendo o maior acúmulo de MS pelas plântulas obtido na profundidade de semeadura de $8,7 \mathrm{~cm}$ resultando em $10,1 \mathrm{~g}$ (Figura $4 \mathrm{~d}$ ). 
a)

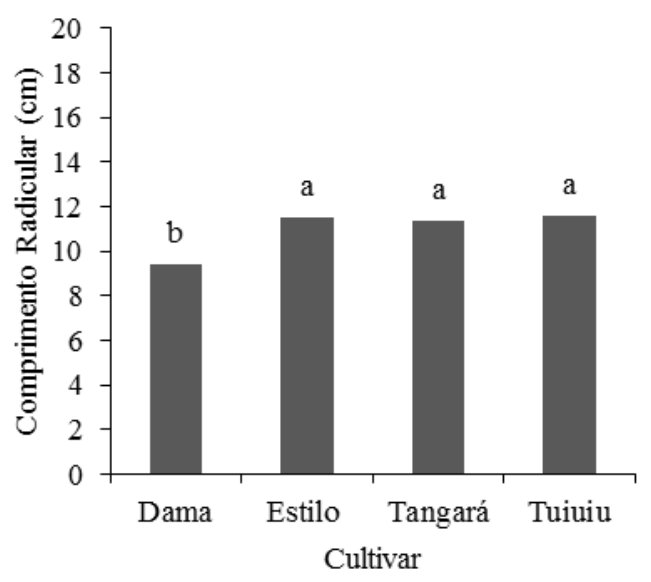

c)

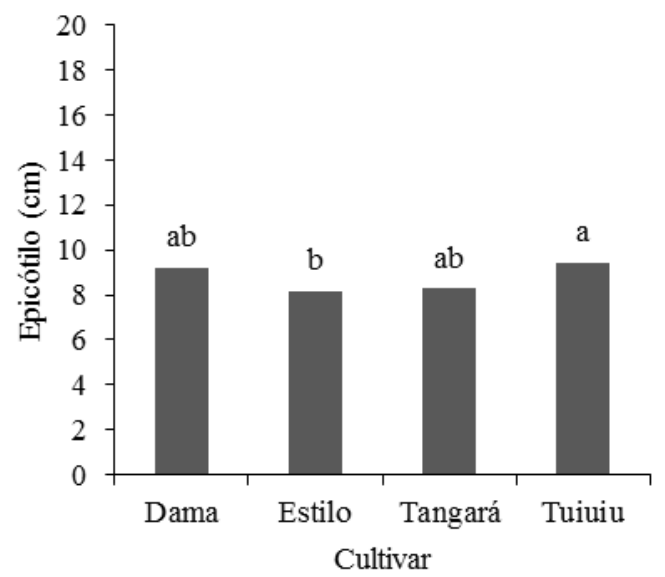

e)

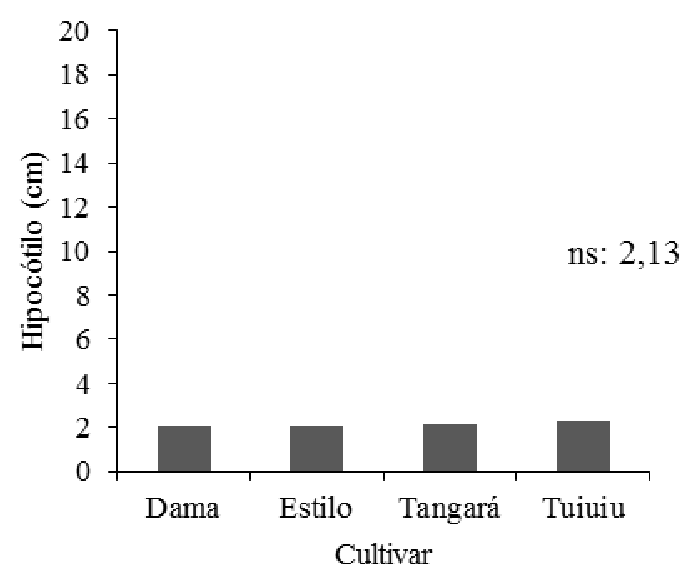

b)

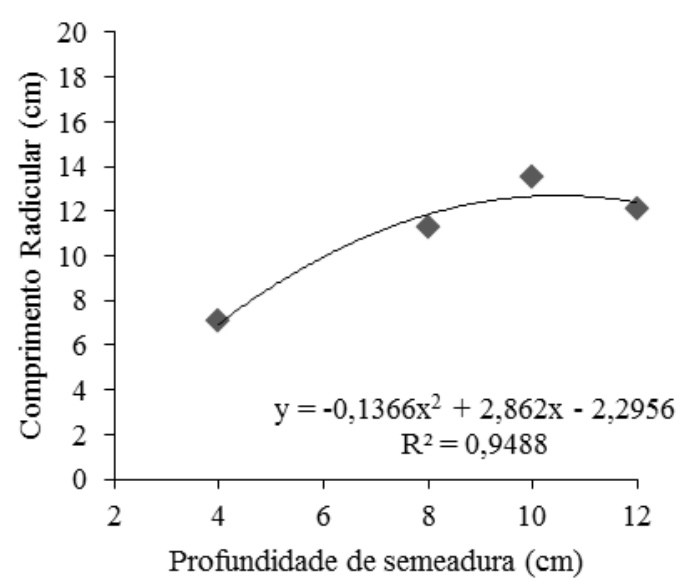

d)

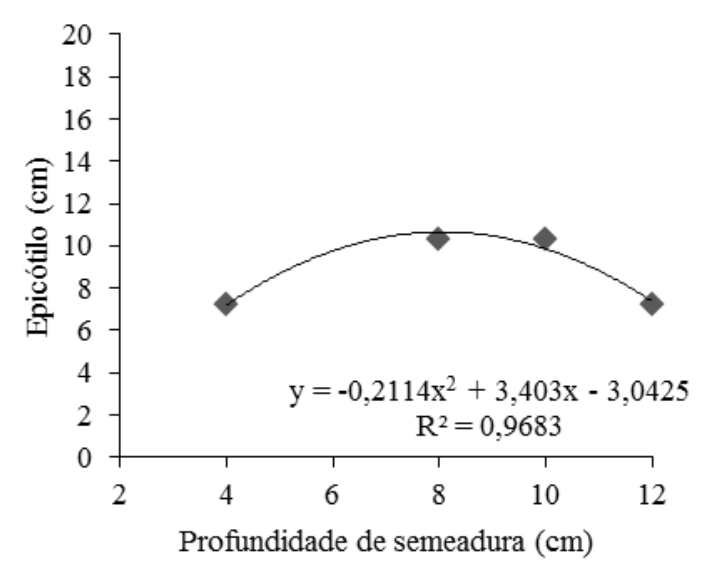

f)

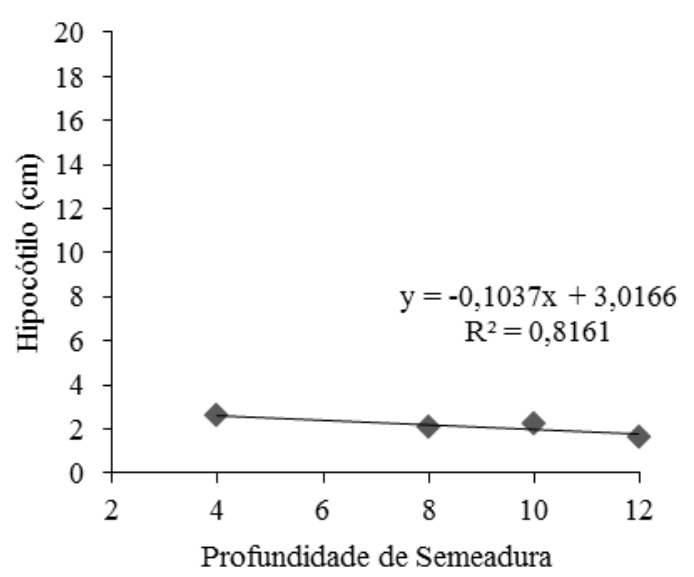

Figura 3. Comprimento de raiz (a; b), de epicótilo (c; d) e hipocótilo (e; f) de plântulas de feijão em função de cultivares e profundidades de semeadura.

Figure 3. Root ( $a$; b), epicotyl ( $c$; d), and hypocotyl (e; f) lengths of common bean seedlings as a function of cultivars and sowing depths. 
a)

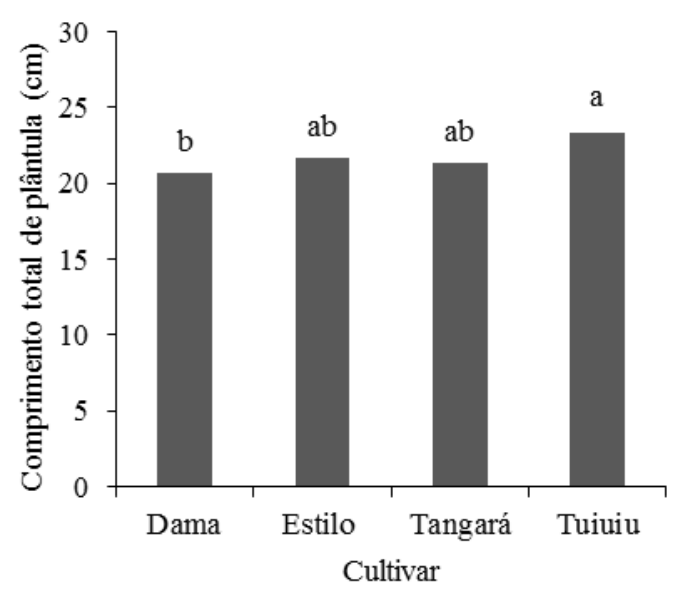

c)

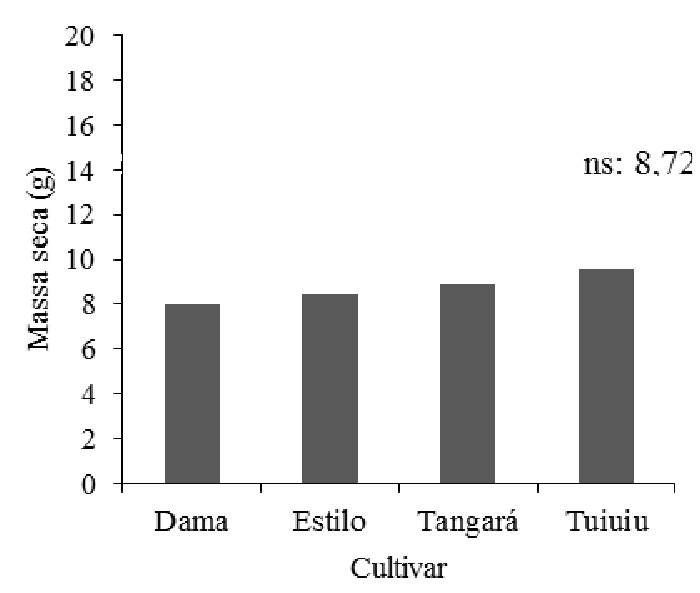

b)

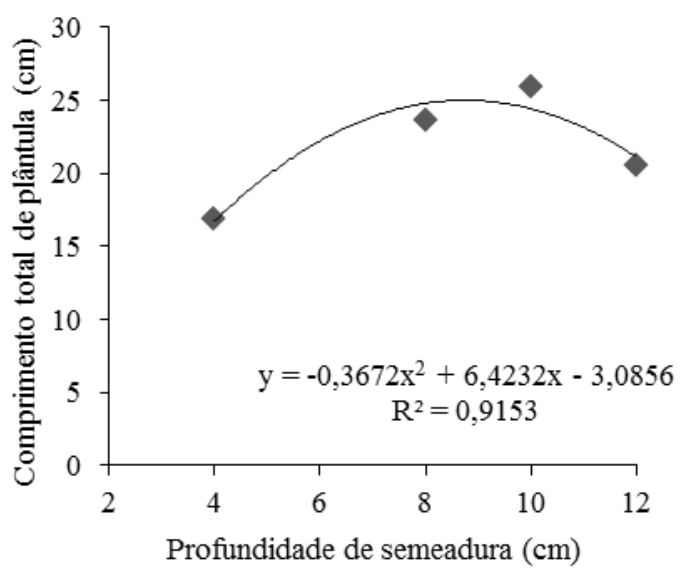

d)

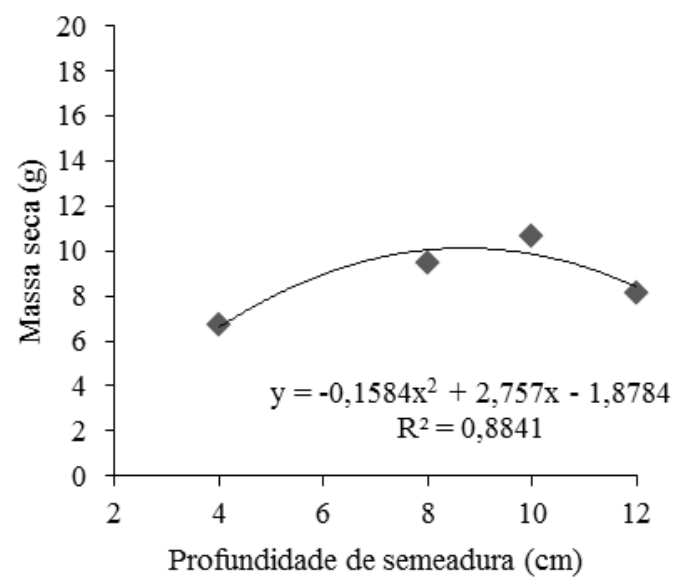

Figura 4. Comprimento total de plântulas $(a ; b)$ e massa seca (c) de plântulas de feijão em função de cultivares e profundidades de semeadura.

Figure 4. Seedling height ( $a ; b)$ and dry weight (c) of common bean seedlings as a function of cultivars and sowing depths.

\section{DISCUSSÕES}

A profundidade de semeadura é específica para cada cultivar, devendo proporcionar germinação e emergência adequada às plântulas (SOUSA et al. 2007, PEDÓ et al. 2014). Neste aspecto, o desempenho apresentado entre as cultivares de feijoeiro testadas diferiu quanto aos parâmetros avaliados, como já observado por BIEZUS et al. (2017).

Conforme as observações para a emergência e IVE das plântulas de feijão, pode-se inferir sobre a interferência de fatores ambientais como temperatura e disponibilidade hídrica, além da espessura de camada de solo sobre estas. Ou seja, sob profundidades rasas as sementes ficam expostas a maior variação de temperatura e umidade, e sob semeaduras mais profundas apresentam-se limitadas pela maior camada de solo, prejudicando a emergência de plântulas ainda frágeis (TILLMANN et al. 1994, SILVA et al. 2008). Assim, a deposição das sementes deve ocorrer em uma profundidade que permita bom contato com solo úmido, mas com adequado fornecimento de oxigênio, promove boa emergência de plântulas (SILVA et al. 2008). Ademais, em profundidades maiores, segundo PEDÓ et al. (2014) a menor emergência possui relação com ao maior obstáculo físico de camadas de solo espessas, prejudicando o estabelecimento, a habilidade competitiva e o potencial produtivo da espécie.

Além disto, o vigor das sementes está relacionado com as reservas destas, e com a capacidade de expressão deste para romper as barreiras físicas, como camadas maiores de solo (PESKE et al. 2012). Ou seja, genótipos com maior capacidade de translocar e armazenar nutrientes nas sementes, apresenta maior potencial de germinação e vigor de plântulas quando sob condições adversas (MARCOS FILHO 2015). Ademais, conforme TEIXEIRA et al. (2010) observaram em sementes de feijão-caupi, a qualidade fisiológica é variável conforme cultivares. Isto pode estar relacionado aos resultados de emergência e IVE observados 
para a cultivar de feijão IPR Tangará, principalmente.

Resultados semelhantes aos observados foram encontrados por ALVES et al. (2014) para emergência e IVE de plântulas de Phaseolus lunatus L., cujos valores foram maiores em profundidades menores, entre 2 e $3 \mathrm{~cm}$, variando conforme a posição do hilo das sementes no solo. Já MODOLO et al. (2011) observaram maior IVE em $5 \mathrm{~cm}$ quando comparado às profundidades de 3 e $7 \mathrm{~cm}$.

Já BIEZUS et al. (2017) verificaram que grupos comerciais Cavalo e Carioca apresentaram diferença no percentual de emergência em relação ao Preto e Jalo, com valores de $80 \%$ e $60 \%$, respectivamente, na profundidade de semeadura de $4 \mathrm{~cm}$, e em relação ao IVE, observaram aumento para os grupos Carioca, Preto e Jalo em profundidades de até $2 \mathrm{~cm}$, e posteriormente decréscimos com o aumento da profundidade, e para o grupo Cavalo, com redução acentuada do IVE a profundidade de $1 \mathrm{~cm}$. Já conforme os estudos de ALI \& IDRIS (2015), não houve efeito significativo de semeaduras em profundidades de 5 e $10 \mathrm{~cm}$ sobre a emergência de plântulas de Vicia faba L..

O resultado para o máximo comprimento da raiz principal das plântulas na profundidade de semeadura de $10,5 \mathrm{~cm}$ pode estar relacionado ao suporte da planta em absorver água e nutrientes além de sintetizar carboidratos (HUGHES et al. 1992). Plântulas de Erythrina verna apresentaram redução no comprimento radicular de $9,6 \mathrm{~cm}$ para $7,2 \mathrm{~cm}$ com o aumento da profundidade de semeadura de $1 \mathrm{~cm}$ para $6 \mathrm{~cm}$ (PÊGO et al. 2015). Já para comprimento da radícula de plântulas de Vicia faba L. com semeaduras em profundidades de 5 e $10 \mathrm{~cm}$ não houve efeito significativo (ALI \& IDRIS 2015).

As observações para o comprimento do epicótilo permitem inferir que pode ter ocorrido estiolamento das plântulas oriundas da semeadura nas profundidades de 8 e $10 \mathrm{~cm}$, pela maior emergência, IVE e altura de plântulas. Ademais, as plântulas necessitam de hastes mais longas para superar a superfície do solo quando da sua colocação em maior profundidade (NÓBREGA \& VIEIRA 1995). Semelhante ao verificado por PÊGO et al. (2015) em plântulas de Erythrina verna, em que houve aumento do epicótilo em semeaduras em profundidades superiores a $3 \mathrm{~cm}$.

Os resultados negativos do aumento da profundidade de semeadura no comprimento do hipocótilo das plântulas de feijão indicam a diminuição da capacidade de emergir em profundidades maiores. Camadas de solo sobrepostas podem se tornar limitações ao desenvolvimento do hipocótilo, pois este deve crescer em comprimento para superar a profundidade de semeadura, e em diâmetro para adquirir força e habilidade para vencer as resistências provocadas pelo peso dos cotilédones e pelo solo (COSTA et al. 1999). Segundo KNITTLE \& BURRIS (1979) as plântulas respondem aos obstáculos físicos do solo, com aumento do diâmetro e diminuição do comprimento do hipocótilo. Tais obstáculos são distintos em função da profundidade de semeadura.

A altura das plântulas de feijão cultivadas sob maiores profundidades de semeadura pode ter apresentado interferência devido a maior barreira física para emergência, além de maior demanda energética (BIEZUS et al. 2017). MODOLO et al. (2011) não encontraram diferenças ao avaliar profundidades de semeaduras de 3,5 e $7 \mathrm{~cm}$ na cultura do feijão, embora observaram a tendência de plântulas com maior altura na profundidade de $5 \mathrm{~cm}$. Contudo, BIEZUS et al. (2017) observaram reduções drásticas na altura de plântulas de feijão com semeaduras a partir de $2 \mathrm{~cm}$ de profundidade após 9 dias da semeadura.

Os resultados para a massa seca de plântulas (MSP) explicam que o acréscimo em profundidades, acima de $8,7 \mathrm{~cm}$ de semeadura interfere na produção de massa seca da cultura, resultando em maior gasto energético realizado pelas plântulas para romper as camadas inferiores de solo, tornando a planta debilitada, com menor acúmulo de matéria seca (GROTTA 2008). Semelhante ao encontrado por ALI \& IDRIS (2015) em que a massa seca de plântulas de Vicia faba L. com semeaduras em profundidades de 5 e $10 \mathrm{~cm}$, não apresentaram efeitos significativos. Contudo, MODOLO et al. (2011) observaram maior MSP de parte aérea de plântulas de feijão na profundidade de semeadura de $5 \mathrm{~cm}$, devido provavelmente à maior altura destas, e não observou diferença para a MS de raiz, embora com tendência de aumento da MSP em maiores profundidades de semeadura. Assim como com plântulas de Erythrina verna em que houve redução da MSP com profundidades de até $6 \mathrm{~cm}$ (PÊGO et al. 2015).

As respostas observadas para o desempenho fisiológico das sementes e desenvolvimento das plântulas das diferentes cultivares de feijão testadas no presente estudo, difere dos obtidos por PINHEIRO et al. (2018) com cultivares de trigo e triticale, e por TEIXEIRA et al. (2010) com feijão-caupi, o que pode estar relacionado às condições do solo do experimento. Assim, destaca-se a relevância de estudos que avaliem o desempenho dos genótipos, definindo profundidades de semeaduras adequadas a cada espécie e cultivar.

Contudo, considerando que o experimento foi realizado com solo peneirado, os valores ideais de 
profundidade que resultaram em melhor desempenho germinativo e do desenvolvimento de plântulas foram ligeiramente superiores aos encontrados nas indicações técnicas de cultivo de feijão. Fato este justificado pela condição do experimento ter sido com solo destorroado e peneirado. Cabe também salientar que o feijão, assim como a soja são espécies que apresentam germinação epígea havendo a necessidade de extensão do hipocótilo no interior do solo a empurrar os cotilédones a efetivação do processo de emergência.

\section{CONCLUSÃO}

Concluiu-se que profundidades de semeadura entre 6 e $10 \mathrm{~cm}$ proporcionam maior emergência e desempenho inicial de plântulas, nas condições deste estudo.

As cultivares de feijão apresentam comportamento similar em todas as profundidades de semeadura.

\section{AGRADECIMENTOS}

Os autores agradecem ao CNPQ/Universal 460983/2014-8; CAPES/Proap e FAPESC/UDESC/PAP, pelo apoio financeiro para a realização da pesquisa. Ao CNPQ pela bolsa de produtividade em pesquisa (SOUZA CA), FAPESC pela bolsa de estudos (MAIER M), CAPES pelas bolsas de estudos (CIGEL C \& KLANDER R).

\section{REFERÊNCIAS}

ALI SAM \& IDRIS AY. 2015. Effect of seed size and sowing depth on germination and some growth parameters faba bean (Vicia faba L.). Agricultural and Biological Sciences Journal 1: 1-5.

ALVES AU et al. 2014. Emergência de plântulas de fava em função de posições e profundidade de semeadura. Bioscience Journal 30: 33-42.

BIEZUS A et al. 2017. Emergência e desenvolvimento inicial de plântulas de feijão em diferentes profundidades de semeadura. Revista Brasileira de Ciências Agrárias 12: 428-434.

CQFS-RS/SC. 2016. COMISSÃO DE QUÍMICA E FERTILIDADE DO SOLO - RS/SC. Manual de adubação e de calagem para os estados do Rio Grande do Sul e Santa Catarina. Porto Alegre: SBCS - Núcleo Regional Sul/UFRGS.

CONAB. 2019. Companhia Nacional de Abastecimento. Acompanhamento da safra brasileira: grãos. Primeiro levantamento. CONAB.

COSTA JA et al. 1999. Comprimento e índice de expansão radial do hipocótilo de cultivares de soja. Ciência Rural 29: 609-612.

EMBRAPA. 2013. Empresa Brasileira de Pesquisa Agropecuária. Sistema Brasileiro de Classificação de Solos. 3.ed. Rio de Janeiro: Embrapa Solos.

FAO. 2019. Food and Agriculture Organization of the United Nations. Rome: FAOSTAT.

GROTTA DCC et al. 2008. Influência da profundidade de semeadura e da compactação sobre a semente na produtividade do amendoim. Ciência e Agrotecnologia 32: 547-552.

HUGHES DF et al. 1992. Role for potassium in the iron-stress response mechanism of iron- efficient oat. Soil Science Society of America Journal 56: 830-835.

INMET. 2019. Instituto Nacional de Meteorologia. Banco de Dados Meteorológicos para Ensino e Pesquisa (BDMEP). Disponível em: http://www.inmet.gov.br. Acesso em: 20 set. 2019.

KNITTLE KH \& BURRIS JS.1979. Soybean hypocotyl growth under field conditions. Crop Science 19: 37-41.

MAGUIRE JD. 1962. Speed of germination-aid in selection and evaluation for seedling emergence and vigor. Crop Science 2: 176-177.

MARCOS FILHO J. 2015. Fisiologia de sementes de plantas cultivadas. 2.ed. Londrina: ABRATES.

MODOLO AJ et al. 2011. Efeito da compactação do solo sobre a semente no desenvolvimento da cultura do feijão. Acta Scientiarum. Agronomy 33: 89-95.

NAKAGAWA J. 1999. Testes de vigor baseados no desempenho das plântulas. In: KRZYZANOSKI FC et al. (Ed.). Vigor de sementes: conceitos e testes. Londrina: ABRATES. p.1-24.

NÓBREGA LHP \& VIEIRA RD. 1995. Avaliação e classificação de cultivares de soja com o tamanho do hipocótilo, sob condições de laboratório e de casa de vegetação. Revista Brasileira de Sementes 17: 160-164.

PEDÓ T et al. 2014. Vigor de sementes e desempenho inicial de plântulas de feijoeiro em diferentes profundidades de semeadura. Revista Brasileira de Ciências Agrárias 9: 59-64.

PÊGO RG et al. 2015. Respostas fisiológicas de plântulas de Erythrina verna em tratamentos pré-germinativos de sementes e profundidade de semeadura. Ciência Florestal 25: 59-66.

PESKE ST et al. 2012. Sementes: fundamentos científicos e tecnológicos. 3.ed. Pelotas: UFPel.

PINHEIRO MG et al. 2018. Initial development of wheat and triticale under different sowing depth. American-Eurasian Journal Agriculture \& Environment Science 18: 206-215.

PURSEGLOVE JW. 1968. Tropical Crops: Dicotyledons. London: Longmans.

R CORE TEAM. 2017. R: A Language and Environment for Statistical Computing. Disponível em: https://www.Rproject.org/. Acesso em: 04 mai. 2018. 
RODRIGUES AJR et al. 2016. Influência da profundidade e posição de semeadura na emergência de Acacia polyphylla DC. Revista Verde de Agroecologia e Desenvolvimento Sustentável 11: 23-29.

SILVA AG et al. 2009. Caracterização físico-química, digestibilidade protéica e atividade antioxidante de feijão comum (Phaseolus vulgaris L.). Alimentos e Nutrição 24: 591-598.

SILVA RP et al. 2008. Efeito da profundidade de semeadura e de rodas compactadoras submetidas a cargas verticais na temperatura e no teor de água do solo durante a germinação de sementes de milho. Ciência e Agrotecnologia 32 : 929-937.

SILVEIRA PM et al. 2018. The effect of longitudinal distribution and seed depth on grain yield of common bean. Journal of Seed Science 40: 90-97.

SOUSA AH et al. 2007. Profundidades e posições de semeadura na emergência e no desenvolvimento de plântulas de moringa. Caatinga 20: 56-60.

TAVARES CJ et al. 2013. Fitossociologia de plantas daninhas na cultura do feijão. Revista Brasileira de Ciências Agrárias 8: 27-32.

TEIXEIRA IR et al. 2010. Desempenho agronômico e qualidade de sementes de cultivares de feijão-caupi na região do cerrado. Revista Ciência Agronômica 41: 300-307.

TILLMANN MAA et al. 1994. Efeito da profundidade de semeadura na emergência de plântulas de tomate (Lycopersicon esculentum Mill.). Scientia Agricola 51: 260-263.

TROGELLO E et al. 2013. Manejos de cobertura vegetal e velocidades de operação em condições de semeadura e produtividade de milho. Revista Brasileira de Engenharia Agrícola e Ambiental 17: 796-802. 